UNIVERSIDADE ESTADUAL DE FEIRA DE SANTANA

Autorizada pelo Decreto Federal $n^{\circ} 77.496$ de $27 / 04 / 76$

Recredenciamento pelo Decreto n"17.228 de 25/11/2016

\title{
PPPG
}

PRÓ-REITORIA DE PESQUISA E PÓS-GRADUAÇÃO

COORDENAÇÃO DE INICIAÇÃO CIENTIFICA

XXIV SEMINÁRIO DE INICIAÇÃO CIENTÍFICA DA UEFS SEMANA

NACIONAL DE CIENTÍFICA E TECNOLÓGICA-2020

\section{DESENVOLVIMENTO E VALIDAÇÃO DE UM NOMOGRAMA PARA PREDIÇÃO DE HIPOGONADISMO MASCULINO.}

\author{
ERDES B. M. S. ${ }^{1}$; OLIVEIRA C. F. A. ${ }^{2}$; NOVAIS M. T. ${ }^{3}$ e BESSA JÚNIOR J. ${ }^{4}$ \\ 1. Pesquisadora bolsista CNPq, Graduando em Medicina, Universidade Estadual de Feira de Santana, e-mail: \\ blendaerdes@hotmail.com \\ 2. Orientadora, DSAU, Universidade Estadual de Feira de Santana, e-mail: claudiacvascular@gmail.com \\ 3. Participante do Grupo de Pesquisa UROS, DSAU, Universidade Estadual de Feira de Santana, e-mail: \\ moniquetonani@yahoo.com.br \\ 4. Coordenador do Grupo de Pesquisa UroS, DSAU, Universidade Estadual de Feira de Santana, e-mail: bessa@uefs.br
}

PALAVRAS-CHAVE: Sintomas do trato urinário inferior, Questionários, Disfunção erétil e Saúde do Homem.

\section{INTRODUÇÃO}

A vitamina D (VD) é um componente corporal em forma de hormônio esteróide que é hidroxilada no fígado a 25-hidroxi-vitamina $\mathrm{D}(25(\mathrm{OH}) \mathrm{D})$, podendo esse composto sofrer reações e se transformar na forma ativa como 1,25-dihidroxi-vitamina D. (WANG et al., 2015). A reação de ativação da VD acontece em algumas regiões do corpo humano, como nos testículos, sendo sua disponibilidade associada com a produção induzida por ultravioleta-B na pele e através da ingesta de alguns alimentos. (LERCHBAUM et al., 2014).

A investigação do status de VD é realizada por meio da mensuração da 25(OH)D (calcidiol) por ser mais biodisponível e sensível ao teste, sendo definido, de acordo com os valores encontrados, como deficientes, insuficientes ou suficientes em VD. (MAEDA et al., 2014). De acordo com esses critérios, é esperado que em torno de um bilhão de pessoas no mundo possuam níveis insuficientes de vitamina D. (JAMES, 2008).

A atuação no organismo da VD acontece por meio do receptor de vitamina D (VDR), que é responsável pela regulação de 3\% do genoma humano. Conforme Lerchbaum et al. (2014), o VDR, juntamente com enzimas envolvidas no metabolismo da vitamina D, são expressos em células de Sertoli, células germinativas, Células de Leydig, espermatozoides e nas células epitaliais que revestem o trato reprodutivo masculino, ratificando assim a importância clínica da atuação endócrina da VD.

Em um artigo pioneiro na abordagem desse tema, Wehr et al (2010), demonstraram em um centro médico de atendimento terciário no sudoeste da Alemanha, relação independente de níveis de $25(\mathrm{OH}) \mathrm{D}$ com testostera. Concomitantemente, em um 
estudo transversal realizado com homens na China, Wang et al (2015), observaram a associação de VD e testosterona, além da alterações gonadais que já eram evidenciadas em ratos.

Diante do quadro global de níveis baixos de VD, bem como da escassez de estudos acerca da relação com a repercussão gonadal, nota-se a necessidade de maior investigação nessa área. Portanto, este estudo visa investigar a relação entre os níveis de $25(\mathrm{OH}) \mathrm{D}$ e a testosterona em homens de nossa região avaliados em programa de rastreio de câncer de próstata.

\section{OBJETIVO GERAL}

- Avaliar aspectos epidemiológicos da associação de níveis de vitamina D e testosterona em homens.

\section{OBJETIVOS ESPECÍFICOS}

- Avaliar a prevalência de deficiência de testosterona em indivíduos do sexo masculino na subpopulação de Feira de Santana/BA;

- Selecionar e identificar o peso de variáveis e fatores de risco associados à deficiência de testosterona masculina e deficiência de vitamina D;

- Apontar a aplicabilidade e acurácia diagnóstica da relação dos níveis de vitamina D e testosterona em homens na conduta clínica.

\section{MATERIAL E MÉTODOS}

Trata-se de um estudo observacional e retrospectivo, onde será realizada a análise de um banco de dados produzido com informações clínicas e laboratoriais, prospectivamente coletados em atendimento clínico de rotina.

Neste banco de dados foram coletados os dados de atendimento clínico de 2014 a fevereiro de 2019 em um centro de atenção à saúde do homem.

O banco de dados foi obtido a partir de pacientes do sexo masculino, onde constam as informações: idade, presença de hipertensão, valor da circunferência abdominal, níveis de glicose e do perfil lipídico, valor de antígeno prostático específico (PSA), valor de ureia, creatinina, vitamina $\mathrm{D}$, além dos valores dos níveis séricos de testosterona. A partir desse banco de dados será realizada inicialmente uma análise quantitativa descritiva, a fim de identificar e descrever a prevalência do hipogonadismo e da hipertensão arterial, bem como a associação das duas condições. Nas comparações Deficiência de Testosterona será definida como testosterona sérica inferior a 300ng/dL, Hipovitaminose D sera considerada quando valores inferiores a 30ng/dl.

Nas análises, as variáveis quantitativas, contínuas ou ordinais serão descritas por medidas de tendência central (média/mediana) e suas respectivas medidas de dispersão 
(variação interquartil, valores máximos e mínimos e desvio-padrão) e as variáveis qualitativas serão descritas através de seus valores absolutos ou porcentagem. A comparação da diferença das variáveis contínuas será efetuada através do teste MannWhitney e $\mathrm{t}$ de Student ou análise de variância (ANOVA). O teste de Fisher ou do quadrado e suas variantes será utilizado para comparar os dados categóricos.

As correlações entre as variáveis ordinais e continuas será dada através do teste de Spearman. Os intervalos de confiança serão estabelecidos em 95\% para medida de precisão dos dados.

Após o estabelecimento dessas correlações será realizada uma análise univariada, sendo que para as variáveis independentes qualitativas isso ocorrerá através da comparação da frequência absoluta e percentual, e para as variáveis quantitativas através da média e desvio-padrão. Odds Ratio será empregada como medida de associação entre as variáveis categóricas. Os valores de p menores que $0.05(\mathrm{p}<0.05)$ serão considerados significativos. Na análise dos dados programa computacional, GraphPad Prism - versão 8.02, GraphPad Software - San Diego - CA/USA será utilizado.

\section{RESULTADOS/DISCUSSÃO}

Foram estudados 1538 indivíduos, com idade de 56,8 8,6 anos. A prevalência de deficiência de VD foi 32,7\% [30-35,1\%] IC 95\%. A prevalência de valores deficientes de TT foi de 22,0\% [20-24,1\%] IC 95\%.

O níveis de TT sérica correlacionaram-se positivamente com os valores de VD $(\mathrm{r}=0,098, \mathrm{p}<0,001)$.

Baixos níveis séricos de VD estão associados a um risco maior de várias doenças crônicas como câncer, diabetes, hipertensão, doenças auto-imunes, osteomusculares e depressão (BARBONETTI et al.,2016).

Entre os tecidos alvos para a VD, o aparelho reprodutor masculino tem sido proposto em decorrência de sua atuação no processo de metabolização da VD (LERCHBAUM et al. 2017). Estudos apontam estreita relação entre os níveis de VD -com os níveis de TT em homens (PILZ et al., 2011).

Em nossa amostra, a hipovitaminose D foi encontrada em 32,7\% [30-35,1\%] IC 95\% dos indivíduos e hipogonadismo em 22,0\% [20-24,1\%] IC 95\% e houve uma associação significativa entre ambas.

Foi identificado que nas pessoas com níveis reduzidos de VD apresentavam TT significativamente menor, tinham maior probabilidade de terem níveis de testosterona total < 300ng/dl e que apresentava relação com valores da $25(\mathrm{OH}) \mathrm{D}$, ainda que fracamente, demonstrando assim associação entre VD e TT.

Em um estudo no leste da China com 2.854 homens foi demonstrado semelhança com nossos resultados com um total de $25,0 \%$ de hipogonadismo e níveis significativos 
de redução de 25 (OH) D (Wang et al. 2015).

Em conformidade com os resultados encontrados neste estudo, Park et al. (2018), em um estudo com 612 homens, detectaram níveis séricos de VD e TT significativamente mais baixos.

Lerchbaum et al. (2017) demonstraram em uma coorte de homens saudáveis de meia idade com níveis normais de TT basais que não houve alteração importante da VD nas concentração de TT, mas que houve diminuição significativa dos marcadores de resistência à insulina. Sendo assim, tal estudo enseja a produção de novos trabalhados que randomize a suplementação com VD em indivíduos hipogonáticos.

Em um estudo com ratos, Liu et al. (2019) demonstraram que a suplementação de vitamina D 3 melhorou a função testicular em ratos diabéticos o que sugere ter como consequência a diminuição dos distúrbios de síntese de testosterona previamente identificado nesses indivíduos.

Foi apontado em uma revisão bibliográfica que o efeito da suplementação de VD nos níveis androgênico masculino não é suficiente para favorecer essa prática em homens hipogonadais. Mesmo assim, reconhece os efeitos da relação VD e TT- (Trummer et al. 2018).

A importância desse tema e dos resultados encontrados são evidenciados pelas associações descritas e os fatores de risco relacionados. Contudo, mesmo com a associação positiva descrita entre $25(\mathrm{OH}) \mathrm{D}$ e TT neste trabalho, em decorrência de alguns entraves e limitações metodológicos como o tipo de estudo e os dados pertencerem a um centro único, sugerimos que o significado clínico desta relação passe por mais investigações.

Estudos do tipo coorte poderão viabilizar essa associação e possíveis relação de causalidade, além disso, ensaios clínicos randomizados são necessários para mensurar o efeito da suplementação da VD sobre a TT_em pacientes com hipogonadismo bem como uma possível função da reposição da TT sobre os valores de 25(OH)D.

\section{CONCLUSÃO}

Neste estudo foi encontrada uma relação importante entre hipovitaminose D e testosterona total em homens avaliados em programa de detecção precoce do câncer da próstata em nosso meio, tanto nos pacientes de meia idade quanto nos idosos. Tais achados sugerem que a dosagem de $25(\mathrm{OH}) \mathrm{D}$ deva ser realizada em pacientes com baixos níveis de TT.

\section{REFERÊNCIAS}

1: WANG, N. et al. Vitamin D is associated with testosterone and hypogonadism in Chinese men: Results from a cross-sectional SPECT-China study. Reproductive Biology 
And Endocrinology, [s.1.], v. 13, n. 1, p.13-74, 16 jul. 2015.

2: LERCHBAUM, E. et al. Serum vitamin D levels and hypogonadism in men. Andrology, [s.1.], v. 2, n. 5, p.748-754, 16 jul. 2014.

3: MAEDA, S. S. et al . Recomendações da Sociedade Brasileira de Endocrinologia e Metabologia (SBEM) para o diagnóstico e tratamento da hipovitaminose D. Arq Bras Endocrinol Metab, São Paulo, v. 58, n. 5, p. 425-428, July 2014.

4: JAMES, WP. 22nd Marabou Symposium: the changing faces of vitamin D. Nut Rev. 2008;66(5):286-90.

5: Wehr E. et al. Association of vitamin D status with serum androgen levels in men. Clin Endocrinol (Oxf). 2010;73:243-8.

6: BARBONETTI, A.; VASSALlO, M. R. C.; FELZANI, G.; FRANCAVILLA, S.; FRANCAVILLA, F. Association between 25(OH)-vitamin D and testosterone levels: Evidence from men with chronic spinal cord injury. Journal of Spinal Cord Medicine, v. 39, n. 3, p. 246-252, 2016. Taylor and Francis Ltd.

7: LERCHBAUM, E.; PILZ, S.; TRUMMER, C.; et al. Vitamin D and Testosterone in Healthy Men: A Randomized Controlled Trial. J Clin Endocrinol Metab, v. 102, n. 11, p. 4292-4302, 2017. Disponível em: <http://www.clinicaltrialsregister.eu>. Acesso em: $31 / 3 / 2020$.

8: PARK, S. G.; YEO, J. K.; CHO, D. Y.; PARK, M. G. Impact of metabolic status on the association of serum vitamin $\mathrm{D}$ with hypogonadism and lower urinary tract symptoms/benign prostatic hyperplasia. Aging Male, v. 21, n. 1, p. 55-59, 2018. Taylor and Francis Ltd.

9: LIU, Y.; HE, Y.; WANG, Q.; et al. Vitamin D 3 supplementation improves testicular function in diabetic rats through peroxisome proliferator-activated receptor- $\gamma /$ transforming growth factor-beta 1/nuclear factor-kappa B. Journal of Diabetes Investigation, v. 10, n. 2, p. 261-271, 2019. Blackwell Publishing.

10: TRUMMER, C.; PILZ, S.; SCHWETZ, V.; OBERMAYER-PIETSCH, B.; LERCHBAUM, E. Vitamin D, PCOS and androgens in men: a systematic review. Endocrine Connections, v. 7, n. 3, p. R95-R113, 2018. Bioscientifica. 